\title{
Adults Play but Not Like Their Young: The Frequency and Types of Play by Belugas (Delphinapterus leucas) in Human Care
}

\author{
Heather Hill $^{1 *}$ and Domonique Ramirez ${ }^{1}$ \\ ${ }^{1}$ St. Mary’s University \\ *Corresponding author (Email: hhill1 @ stmarytx.edu)
}

Citation - Hill, H., \& Ramirez, D. (2014). Adults Play but Not Like Their Young: The Frequency and Types of Play by Belugas (Delphinapterus leucas) in Human Care. Animal Behavior and Cognition, 1(2), 166-185. doi: 10.12966/abc.05.07.2014

\begin{abstract}
While play occurs in many taxa with younger conspecifics engaging in play behaviors more often than older conspecifics, little empirical research currently exists on play by white whales, or belugas, (Delphinapterus leucas). The purpose of the current study was to explore the types of play exhibited by a group of belugas in human care. Archived video footage representing 24.5 hours of observation time collected over three years for 14 belugas (5 immature and 9 adults) was coded for type, frequency, and duration of all play events. Out of 2,092 play events, the belugas produced 497 bouts of play and preferred to engage in independent forms of play (92\%) as opposed to coordinating their activities together $(8 \%)$. Immature belugas exhibited four times as many play bouts $(n=405)$ compared to adult play events $(n=92)$ and included motor play, water play, and object play as well as some social interactions (e.g., play chases). When compared to all types of play, play with objects represented $50 \%$ of the bouts, and when the degree of diversity of play was considered all belugas showed more diversity with environmental enrichment devices (EEDs) present (83\% of diverse play bouts) than when exhibiting motor or water play. Age and sex of the belugas also influenced the type of play (i.e., motor, water, or EEDs) exhibited during different degrees of complexity of play bouts (i.e., single events, repetitive bouts, diverse bouts, and complex cooperative social play). When sex of the beluga was considered, males appeared to prefer to engage in motor play while females appeared to prefer to engage in object play during single play events (males: $n=68,64 \%$, females: $n=55,52 \%$ ) and repetitive bouts (males: $n=18,62 \%$, females: $n=20,54 \%$ ). Some complex cooperative play bouts between immature belugas and between immature and adult belugas $(n=42,10 \%)$ were observed. Play bouts involving EEDs lasted significantly longer $(M=55.38 \mathrm{sec}, s=2.85)$ and produced greater diversity in play behaviors for all belugas combined. In summary, belugas of all ages engage in spontaneous play behaviors, but the age and sex of each beluga produce different play preferences.
\end{abstract}

Keywords - Age, Beluga, Complexity, Delphinapterus leucas, Diversity, Play, Sex

Play occurs in many different taxa of animals and is hypothesized to serve many different functions. As summarized by Burghardt (2005), play is notoriously difficult to define, but seems to be best characterized by the following definition: "Play is repeated, incompletely functional behavior differing from more serious versions structurally, contextually, or ontogenetically, and initiated voluntarily when the animal is in a relaxed or low-stress setting." (Burghardt, 2005, p. 82). Play has been observed in an increasing number of species including birds, reptiles, insects, cephalopods (e.g., octopus) and most, if not all, mammals, both terrestrial and aquatic (Burghardt, 1998, 2005; Fagen, 1981; Greene, Mellilo-Sweeting, \& Dudzinski, 2011; Heinrich \& Smolker, 1998; Kuczaj \& Makecha, 2008; Kuczaj, Makecha, Trone, Paulos, \& Ramos, 2006; Mackey, Makecha, \& Kuczaj, 2014). 
The proposed functions of play are myriad and encompass all aspects of behavior, sociality, emotions, and cognition. In terms of behavior, play is thought to enhance the motor development (e.g., muscle strength and coordination of actions), the physiological development (e.g., endurance), the integration across sensory systems, experience with adult-like roles (e.g., parenting, fighting), communication skills and interpretation (e.g., responding appropriately to social cues), degree of dominance status, acquisition of information about objects and conspecifics, neural development (e.g., strengthening cortical pathways and memory), flexible thinking and integration of information across contexts, creation of novel responses to environmental challenges, and the determination of normative development (as summarized by Burghardt, 2005; Martin \& Caro, 1985). Whether the function of play involves one or all of these mechanisms continues to be a matter of debate as most of the proposed functions have not been assessed experimentally (Bekoff \& Byers, 1998; Burghardt, 2005; Power, 2000; Spinka, Newberry, \& Bekoff, 2001). Despite the lack of agreement on the function of play, it is clear that when health status, access to nutrition, habitat, and social groupings are compromised, the frequency and quality of play often drops (Biben \& Champoux, 1999; reviewed by Held \& Spinka, 2011; Sommer \& Mendoza-Granados, 1995), as expending resources on an energy-costly behavior like play is not beneficial to survival (but see Burghardt, 2005 for exceptions). In contrast, if play is present in animal populations within human care, then the environment of those animals is limited in level of stress and is enriching or stimulating (Held \& Spinka, 2011; Greene et al., 2011; Rauw, 2013; Sommer \& MendozaGranados, 1995).

Play behavior encompasses many different activities, including locomotor actions, object play, predatory, and social play (Bekoff \& Byers, 1998; Burghardt, 2005). Locomotor play includes physical activities such as swinging, rolling, chasing, jumping, or any other variations involving physical motor movements (Bekoff \& Byers, 1998; Burghardt, 2005; Loizos, 1967). Although these activities are part of the species-typical behavioral repertoire, they are considered play when they are exaggerated, repeated, and do not appear to have a clear purpose other than for the sake of enjoyment (Bekoff \& Byers, 1998; Burghardt, 2005). Object play generally entails manipulating inanimate objects within the animal's environment in non-functional activities (Bekoff \& Byers, 1998; Burghardt, 2005; Fagen, 1981). Objects are often natural parts of an environment, such as twigs, leaves, bugs, stones, and water, but may also include human-constructed objects, such as environmental enrichment devices (i.e., EEDs or toys) and habitat features (e.g., gates, ledges) (Bel'kovich, Ivanova, Kozarovitsky, Novikova, \& Kharitonov, 1991; Burghardt, 1998, 2005; Delfour \& Aulagnier, 1997; Fagen, 1981; Greene et al., 2011; Heinrich \& Smolker, 1998; Kuczaj \& Makecha, 2008; Kuczaj et al., 2006; Mann \& Smuts, 1999; Norris, 1994; Pace, 2000). Predatory play generally involves the practice of hunting skills with objects that are not typically prey or with prey that are not consumed. A variety of mammals (e.g., cats, Felis domesticus, Caro, 1980; dolphins, Tursiops truncatus, Mann \& Smuts, 1999) and birds (e.g., herring gulls, Larus argentatus, Gamble \& Cristol, 2002) have been observed to exhibit predatory play. Finally, social play involves the interaction between two or more animals in which behaviors from other contexts are combined in novel sequences or used in different contexts (Bekoff, 1978, 1995; Bekoff \& Allen, 1998; Pellis \& Pellis, 1987). Social play often involves specific behaviors from a species' socio-sexual, aggressive, or predatory repertoire (as reviewed in Pellis \& Pellis, 2013). For example, domesticated and wild rats attack the nape of the other rat's neck during play fights (i.e., a courtship behavior) versus attacking the rump of the other rat during agonistic fights (Himmler et al., 2013; Pellis \& Pellis, 1987). Many species display fast-paced chases or rough and tumble play that are also part of their aggressive and predatory repertoires (e.g., red colobus monkeys, Procolobus rufomitratus, Worch, 2012; members of the Macropodoidea family, kangaroos, wallabies, rat-kangaroos, Watson, 1998).

Each type of play may be performed independently or socially. Greene and colleagues (2011) recently reviewed the benefits of each context. Overall, independent or solitary play is hypothesized to increase cognitive flexibility as the animals have control over their actions (Kuczaj \& Makecha, 2008). Animals engaged in solitary play may produce single play events, repeat the same play event, or may combine different types of play events in an effort to challenge their skills or promote cognitive growth (Kuczaj \& Makecha, 2008). As Piaget (1952) argued for human children, moderately discrepant events 
produce the greatest cognitive growth as they balance current skills with the ability and motivation to solve a problem that is challenging yet not overwhelming. When play bouts are socially driven, not only must the initiators be aware of their own behaviors, but they must also be ready to respond to the responses of their partner that may involve both expected and unexpected behaviors. Social play also provides the opportunity for conspecifics to evaluate each other's current level of strength and to practice less developed behaviors in safe social interactions while building bonds for future relationships or alliances (Bekoff \& Byers, 1998; Biben, 1998; Burghardt, 2005; Fagen, 1981; Pellis \& Pellis, 1998).

Play typically peaks during mid-to late infancy and again during the juvenile period for many species (Biben, 1998; Byers \& Walker 1995; Burghardt, 2005; Fagen, 1981; Pellis \& Pellis, 2013; Power, 2000; Worch, 2012). Prior to its initial peak, play is less likely to occur as the young animals are expending most of their resources on physical development (Burghardt, 2005). However, play does occur very early in development as illustrated by wild beavers (Castor canadensis) that engaged in some component of play two hours after birth (Patenaude, 1984) and spotted hyena cubs (Crocuta crocuta) that displayed social play at two weeks of age, locomotor play at three weeks, and object play at four weeks (Drea, Hawk, \& Glickman, 1996). The ontogeny of different types of play is likely related to the development of different behavior systems as different types of play emerge, peak, and decrease across age (as reviewed in Burghardt, 2005). Moreover, differences in the timing of the emergence of various types of play exist among species of different taxa, suggesting that specific behaviors are emphasized during critical periods of development (Burghardt, 2005). Neurological evidence has corroborated the importance of critical periods for play by rats (reviewed by Burghardt, 2005; Byers \& Walker, 1995; Pellis \& Pellis, 2011; Pellis, Pellis, \& Bell, 2010; Siviy, 1998). Most of these developmental changes occur during the early period of development, with play peaking during the juvenile period for most species, and decreasing during the adult period (Burghardt, 2005; Fagen, 1981; Hall, 1998). While adults do not play as often as younger conspecifics, adults do play with objects and with conspecifics (Burghardt, 2005; Fagen, 1981; Greene et al., 2011; Hall, 1998; Kuczaj et al., 2006; Walters, 1987). When compared to play by young conspecifics, adult play is usually more efficient in its topography and occurs more often with domesticated and captive animals than animals in their natural habitat (Burghardt, 2005; Fagen, 1981; Greene et al., 2011; Hall, 1998; Himmler et al., 2013; Kuczaj et al., 2006; Mancini \& Palagi, 2009; Paulos, Trone, \& Kuczaj, 2010). Unfortunately the limited research has not delineated whether adults should exhibit more complex forms of play or more repetitive forms of behavior. Rather, most research has indicated that adult play may be related to high arousal states and environmental stimuli that stimulate play behavior (Burghardt, 2005; Fagen, 1981; Hall, 1998; Palagi, 2009).

As identified by Burghardt (2005), the explanation of "sex differences in play fighting (amount and type of play fighting and choice of partners) is considered one of the greatest accomplishments of modern animal play research (Caro, 1988; Pereira \& Fairbanks, 1993; P. K. Smith, 1982)” (p. 162). Sex differences in play behaviors have consistently been found with males usually exhibiting rough and tumble forms of play and play fighting more often than females (Byers, 1984; Gibson \& Mann, 2008; Hasset, Seibert, \& Wallen, 2008; Meaney, Stewart, \& Beatty, 1985). This male bias in social play seems to be mediated by hormone levels, specifically testosterone or other androgens (reviewed by Burghardt, 2005) but may also reflect socialization differences (Hasset et al., 2008). Research with spotted hyenas has supported the hormonal influence on female characteristics; female spotted hyenas are dominant over males, have enlarged genitalia, and display masculinized behaviors, including play fighting and locomotor play at levels greater than male spotted hyenas (Pederson, Glickman, Frank, \& Beach, 1990). Locomotor play and object play have evidenced some sex differences, but these differences are not as consistent as the differences found in social play (Burghardt, 2005; Fagen, 1981; Rauw, 2013). In two groups of dolphins, sex differences in frequency of object play appeared with captive male Atlantic bottlenose dolphins exhibiting more object play than their female conspecifics and wild female Atlantic spotted dolphins (Stenella frontalis) exhibiting more object play than their male conspecifics (Greene et al., 2011). It is unclear if these sex differences were due to sampling protocols or habitat and species differences between each population. Other evidence comes from young kittens in which males displayed greater levels of object play than females between two and three months (Bateson, 1981), and gelada 
baboons (Theropithecus gelada) in which adult females initiate most of the social play bouts with adult female and immature baboons (Mancini \& Palagi, 2009).

While age differences and sex differences exist, few animal studies have examined the progression of play behaviors from when they are first produced to when they are mastered (Burghardt, 2005; Fagen, 1995; Power, 2000). Parten (1932) and Piaget (1951) each described sequences through which human children progress to create increasingly complex play behaviors. Parten (1932) suggested that during the first three years of life, children move from solitary play involving objects or locomotion/body movements to parallel play in which they play alongside other children independently to interactive associative play in which they share the same toy or mimic each other's actions to cooperative play where children engage in play bouts that follow the same rules and turn-taking. Piaget (1951) discussed the importance of sensorimotor development and cognitive development in aiding the growth of children's behavior from simple reflexes to intentional and coordinated behaviors involving others. Both models have been proposed as potential paradigms to be applied to animal play, but few researchers have attempted to apply them (Parker \& Gibson, 1990; Parker \& McKinney, 1999; Kuczaj \& Trone, 2001; Kuczaj \& Walker, 2006). Two variations of these androcentric models were proposed by Fagen (1995) and Mitchell (1990). Fagen (1995) proposed a hierarchical scheme with which to classify the complexity of animal play while Mitchell (1990) proposed a hierarchical scheme that emphasized the role of intentionality in play behavior. Unfortunately, these classification schemes have yet to stimulate research with animals that tests their predictions (Burghardt, 2005; Power, 2000).

Early reports on cetacean behavior suggested that dolphin calves were prone to play and produce novel and increasingly complex behaviors (McBride \& Hebb, 1948; Tavolga, 1966). More recently, Kuczaj and colleagues studied a group of captive bottlenose dolphins for more than five years and followed the progression of play behaviors from the birth of several calves through their juvenile period (Kuczaj \& Makecha, 2008; Kuczaj et al., 2006; Kuczaj \& Trone, 2001; Kuczaj \& Yeater, 2006; Mackey et al., 2014). The results of these studies indicated that dolphin calves modified their initial simple play behaviors by producing increasingly complex behaviors after mastering the simple behavior. Adults were also observed to produce novel behaviors that they then varied in topography. Another group of captive adult bottlenose dolphins was observed to manipulate the quality of their underwater bubble rings suggesting that these animals were also varying the complexity of their self-made objects (McCowan, Marino, Vance, Walke, \& Reiss, 2000). In general, anecdotal reports indicate that a variety of cetaceans display play behaviors, including social play, object play, and locomotor play. However, limited research has focused on the topography, frequency, or developmental trajectory of spontaneous play behavior in cetaceans (Bel'kovich et al., 1991; Greene et al., 2011; Herzing, 1997; Kuczaj \& Makecha, 2008; Kuczaj et al., 2006; Kuczaj \& Trone, 2001; Kuczaj \& Yeater, 2006; Marten, Shariff, Psarakos, \& White, 1996; McCowan et al., 2000; Pace, 2000; Paulos, Trone, \& Kuczaj, 2010; Yeater \& Kuczaj, 2010). Like dolphins, white whales or belugas have been observed to display play behaviors both in their natural habitat and in human care (Delfour \& Aulagnier, 1997; Hill, 2009; Hill, Campbell, Dalton, \& Osborn, 2013; Hill et al., 2011; Krasnova, Bel'kovich, \& Chernetsky, 2009; Norris, 1994). Belugas exhibit all forms of play, including locomotor activities, object play, and social play. However, a concentrated study of beluga spontaneous play has not been conducted.

The purpose of the current study was to explore the influence of age and sex of belugas on the spontaneous play exhibited by a population of belugas in human care. Using archived video footage collected over a three-year period, the play behavior of 14 belugas, ranging in age between 6 months and 25-30 years, was coded to assess the frequency and type of play behavior exhibited. The frequency of events, duration, type of play, participants involved, and degree of complexity were evaluated for each play bout observed. 
As an exploratory study, the primary objective was to describe the different types of play exhibited by this group of belugas. A series of hypotheses derived from previous studies of cetacean and mammalian play were tested.

1. Solitary play was expected to occur more often than cooperative play.

2. The different types of play were expected to be produced in different proportions.

3. Simple independent play was expected to occur more often than diverse or complex forms of play.

4. Younger belugas were expected to exhibit play bouts more frequently than adult belugas.

5. An age difference was expected to emerge for diverse and complex forms of play (i.e., locomotor play, water play, object play, or social play).

6. Sex differences were expected to emerge in play behaviors, including preferred forms of play.

\section{Subjects and housing}

\section{Method}

Fourteen belugas were housed at a facility in Texas, which consisted of five intersecting pools containing over 7,570,823 liters (more than 2,000,000 gallons) of man-made saltwater maintained at a temperature of $18{ }^{\circ} \mathrm{C}+/-1^{\circ} \mathrm{C}$ (Figure 1). The belugas consisted of a calf $(D l 1)$, four juveniles $(D l 2, D l 3$, $D l 4, D l 5)$, two adult males $(D l 8, D l 10)$, and seven adult females $(D l 6, D l 7, D l 9, D l 11, D l 12, D l 13, D l 14)$ between the years of 2010-2013 (Table 1). The whales were housed in dynamic social groupings, ranging between two and eight belugas in one to three connected pools. The calves were always paired with their mothers. Thus, social groupings for this study may have included multiple mother-calf pairs or multiple mother-calf pairs with other adults and calves.

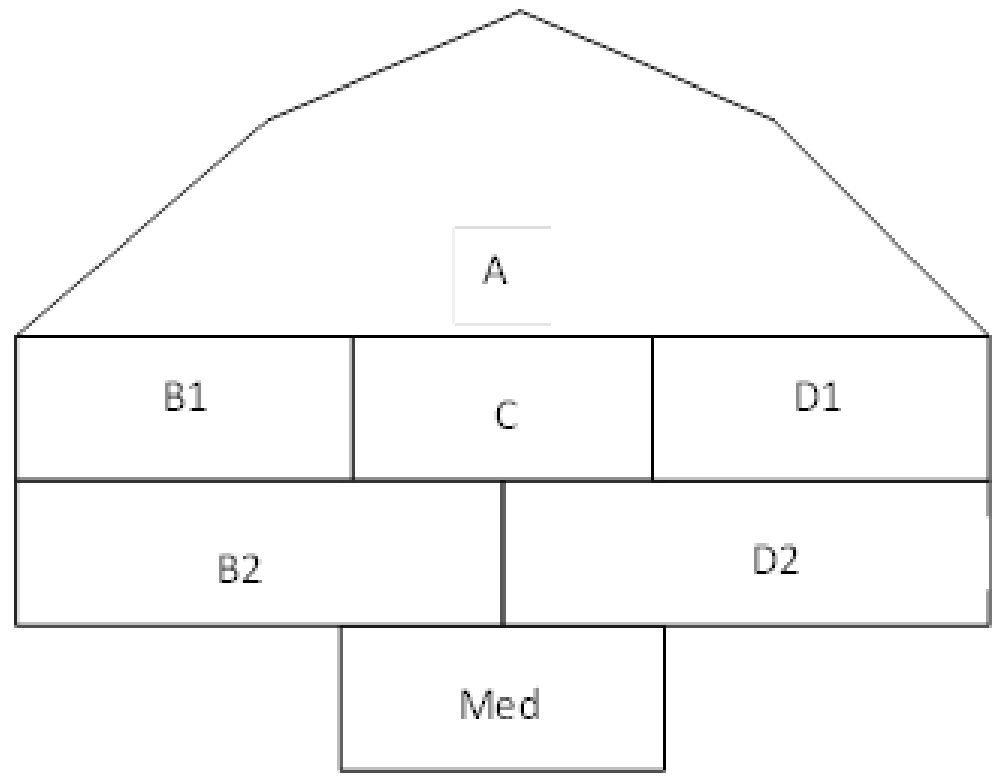

Figure 1. Schematic of facility in which belugas were housed. Not drawn to scale. 
Hill \& Ramirez 171

Table 1

Demographics for Beluga Whales

\begin{tabular}{|c|c|c|c|c|c|}
\hline \multirow{2}{*}{ Animal } & \multirow{2}{*}{ Sex } & \multirow{2}{*}{ Age Classification } & \multicolumn{3}{|c|}{ Age (years) } \\
\hline & & & 2010-2011 & 2011-2012 & $2012-2013$ \\
\hline$D l 1$ & Female & Immature & $6 \mathrm{mo}$ & 1 & 2 \\
\hline$D l 2$ & Female & Immature & 1 & 2 & 3 \\
\hline$D l 3 *$ & Female & Immature & 2 & -- & -- \\
\hline$D l 4 *$ & Male & Immature & 3 & -- & -- \\
\hline Dl5 & Male & Immature & 3 & 4 & 5 \\
\hline$D l 6$ & Female & Adult & 10 & 11 & 12 \\
\hline$D l 7$ & Female & Adult & 11 & 12 & 13 \\
\hline$D l 8 *$ & Male & Adult & 18 & -- & -- \\
\hline$D l 9$ & Female & Adult & $\sim 26$ & $\sim 27$ & $\sim 28$ \\
\hline$D l 10 *$ & Male & Adult & -- & $\sim 23$ & $\sim 24$ \\
\hline$D l 11^{*}$ & Female & Adult & $\sim 26$ & -- & -- \\
\hline Dl12 & Female & Adult & $\sim 26$ & $\sim 27$ & $\sim 28$ \\
\hline$D l 13 *$ & Female & Adult & $\sim 26$ & -- & -- \\
\hline Dl14 & Female & Adult & $\sim 29$ & $\sim 30$ & $\sim 31$ \\
\hline
\end{tabular}

Note. Animals denoted by an asterisk (*) were not present at the facility for all data collection years.

\section{Materials and Measures}

A total of $24.5 \mathrm{hrs}$ of archived video recordings were selected for coding. These archived video recordings had been collected since 2007 on every mother-calf pair housed at this facility (i.e., over 1200 videos). The recordings were collected using a focal follow approach (Altmann, 1974/1996) for each mother-calf pair. Mother-calf pairs and their companions were videotaped at different times of day, on average for $15 \mathrm{~min}$ a session, with sessions ranging between 4 and $30 \mathrm{~min}$ in length. Sessions were videotaped from above water (all pools but Pool A) or through the underwater viewing windows available in Pool A (Figure 1). While a focal follow technique was utilized to concentrate on a mother-calf pair, a wide angle recording technique was often used to maximize the visible field. Although this approach does not guarantee equal sampling for all animals in the social grouping, it does ensure that all animals are represented throughout the video recordings. Eight video recordings per month between the years of 2010 and 2013 were randomly selected for a total of 288 sessions. From these 288 sessions, the videos were event-sampled for play behavior. Thus, 111 sessions were ultimately coded for play behavior.

Operational definitions of the types of play and the complexity of play categories may be found in Table 2. Specific definitions for each play behavior may be found in Mann and Smuts, 1999, Greene et al., 2011 Kuczaj et al., 2006, and Kuczaj and Trone, 2001. A play event was defined as the display of one discrete play behavior. A play bout constituted a play event or a set of play events that were performed contiguously until the bout was terminated when the initiating animal left the play bout to perform another class of behavior (e.g., solitary swim or swim with other animal). As described by previous researchers, social play can incorporate behaviors from the species-typical repertoire (e.g., socio-sexual, aggression, or foraging contexts) in atypical contexts or in novel sequences (Bekoff, 1978, 1995; Bekoff \& Allen, 1998; Pellis \& Pellis, 1987). To differentiate between play behaviors from species-typical behaviors, several criteria were used: 1) the receiving animal reciprocated the initiating animal's social interaction, 2) the receiving animal did not flee from the initiating animal, 3) the receiving animal did not respond with an escalated aggressive response, or 4) the species-typical behavior was performed atypically (e.g., head thrust was performed repetitively as if splashing water while it rained and another calf was within a body length). Ambiguous social interactions were not coded as a play bout.

Each type of play was coded for frequency and duration. Complexity of play was determined by the frequency and variability of play events performed during a bout. Thus, a single play event was the simplest form of play while repetitive and diverse accounted for multiple play events in a bout that included play events within or across different classes of play, respectively. Finally, complex cooperative 
or social play was considered the most complex form of play as it required the reciprocal interaction of another beluga.

When the belugas were not playing with another animal, the play behavior was categorized as independent or solitary. Age classification was determined by sexual maturity. Animals that had not reached sexual maturity were considered immature and animals that had reached sexual maturity were adults.

Table 2

Operational Definitions of Types of Play and Complexity of Play

Categories

Types of Play

Locomotor play

Water Play

Object Play

\section{Complexity of Play Bouts}

\author{
Single Event \\ Repetitive Bouts
}

Diverse Bouts

Complex Cooperative/Social Play

Operational Definition

\author{
High energy behaviors that are exaggerated, dynamic \\ versions of typical species-specific body-oriented behaviors \\ (e.g., fast swims, aerials, body slaps, spinning in circles in a \\ vertical position, slide outs, and surfing) \\ Manipulation of water or release of air underwater to alter the \\ form (e.g., water spits water tosses, water splashes, bubbles, \\ biting, pushing, or watching bubbles, bubble fountain, and \\ bubble rings) \\ Manipulation of inanimate objects found within their \\ environment (e.g., feathers, fish, gates, leaves, and \\ environmental enrichment devices, EEDs, provided by \\ humans)
}

One play behavior is exhibited (e.g., 1 buoy toss or 1 water spit)

One play behaviors that is repeated contiguously and consistently for the bout (e.g., 20 water tosses or 5 vertical spins)

More than one play behavior is combined during the same play bout (e.g., an aerial and a spin swim combined in the same bout or a slide out to retrieve an object).

High energy, pleasurable interactions between two or more animals in which the participants display species-typical behaviors (e.g., courtship, aggression, foraging) in unusual contexts or in novel sequences in response to each other's actions (e.g., chasing, play fighting, a mother and calf mouthing the same object; tug-a-war with the gate)

Note. Definitions of specific cetacean behaviors may be found in Mann and Smuts, 1999; Greene et al., 2011; Kuczaj et al., 2006, and Kuczaj and Trone, 2001.

\title{
Procedure
}

One research assistant coded $85 \%$ of the selected sessions from the archived video footage. Two additional research assistants independently coded the remaining $15 \%$ of the video footage. Each selected video was then viewed to determine if play behavior occurred. Only videos in which play behavior was visible on the video footage was coded for the type of play, the complexity of play, the initiator, the initiator's age classification, the frequency of each play event, the length of the bout, and participants involved. All play events were coded using separate variables to ensure independence of observations. For example, if a repetitive play bout was observed, the 20 water tosses were not counted individually, but rather categorized as one bout of repetitive water play. Similarly, if a social play bout occurred, the bout was included only once in the dataset with the participant information included. Thus, if two belugas 
were involved in a cooperative complex play bout, the bout was counted only once and the two belugas were recognized as participants of that bout.

All data were entered into Microsoft Excel 2010 and then analyzed with IBM SPSS 19® using the compiled dataset. The data were analyzed using a series of chi square goodness of fit tests, chi square tests of independence, and a 4 (play bout) x 3 (type of play) x 2 (sex) x 2 (age) ANOVA with a follow-up 1-way ANOVA using Dunnet's T3 post hocs to evaluate the proposed hypotheses. All duration data met the assumption for normality.

\section{Results}

\section{General descriptive statistics}

Play bouts occurred in $38.5 \%$ of the selected video sessions and represented a total of 182.2 minutes, or $12 \%$ of the total video footage selected. A total of 2,092 independent play events were recorded. When the events were categorized into bouts, a total of 497 bouts were examined. This represents an overall play rate for this population of belugas of 0.34 play bouts per minute, using the total available footage selected (i.e., $24.50 \mathrm{hr}$ ). Overall, the belugas displayed significantly more independent events $(n=455,92 \%)$ than cooperative events $(n=42,8 \%)$, binomial test, $p<0.0001$, as anticipated from previous cetacean studies.

\section{Types of play}

As expected, the belugas in the current study displayed different types of play, including locomotor play, water play, object play, and social play (Figure 2). When compared to all types of play, object play $(n=249)$ represented $50 \%$ of the bouts, locomotor play $(n=125)$ represented $25 \%$ of the bouts, water play $(n=71)$ represented $14 \%$, and social play $(n=42)$ represented $8 \%$ of the bouts. The belugas engaged in significantly more object play than expected by chance, $\chi^{2}(3, N=497)=202.52, p<$ 0.001. Object play consisted mostly of EEDs provided by the trainers with a few instances of play involving gates or leaves.

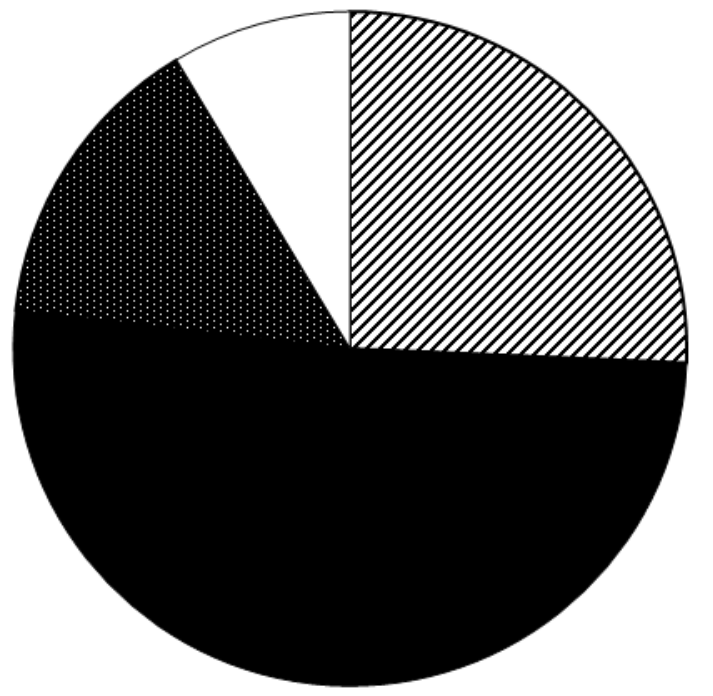

$\boldsymbol{\nabla}$ Locomotor Play

Object Play

Water Play

Social Play

Figure 2. Percent of type of play categories. 


\section{Complexity of play}

Single event play bouts $(n=213,43 \%)$ were the most frequently occurring category of degree of complexity of play with diverse play bouts occurring next most often $(n=176,35 \%)$, as expected. Repetitive play bouts $(n=66,13 \%)$ and complex cooperative social play bouts $(n=42,8 \%)$ occurred significantly less often than single event play bouts, $\chi^{2}(3, N=497)=166.69, p<0.001$. Using a series of chi square goodness of fit follow-up tests, we found that when type of play was examined within each category of degree of complexity of play (Figure 3), the belugas showed more diversity in their play when EEDS were present ( $n=146,83 \%$ of diverse play bouts) than when exhibiting locomotor $(n=19,11 \%)$ or water play $(n=11,6 \%), \chi^{2}(2, N=176)=195.60, p<0.001$. The presence of EEDS was also associated with more complex cooperative social play than locomotor $(n=12,29 \%)$ or water play $(n=3$, $7 \%), \chi^{2}(2, N=42)=21.00, p<0.001$. In contrast, belugas engaged in all types of play relatively equally during repetitive bouts and showed a preference for locomotor play $(n=103,48 \%)$ when displaying single event play bouts, $\chi^{2}(2, N=213)=35.27, p<0.001$.

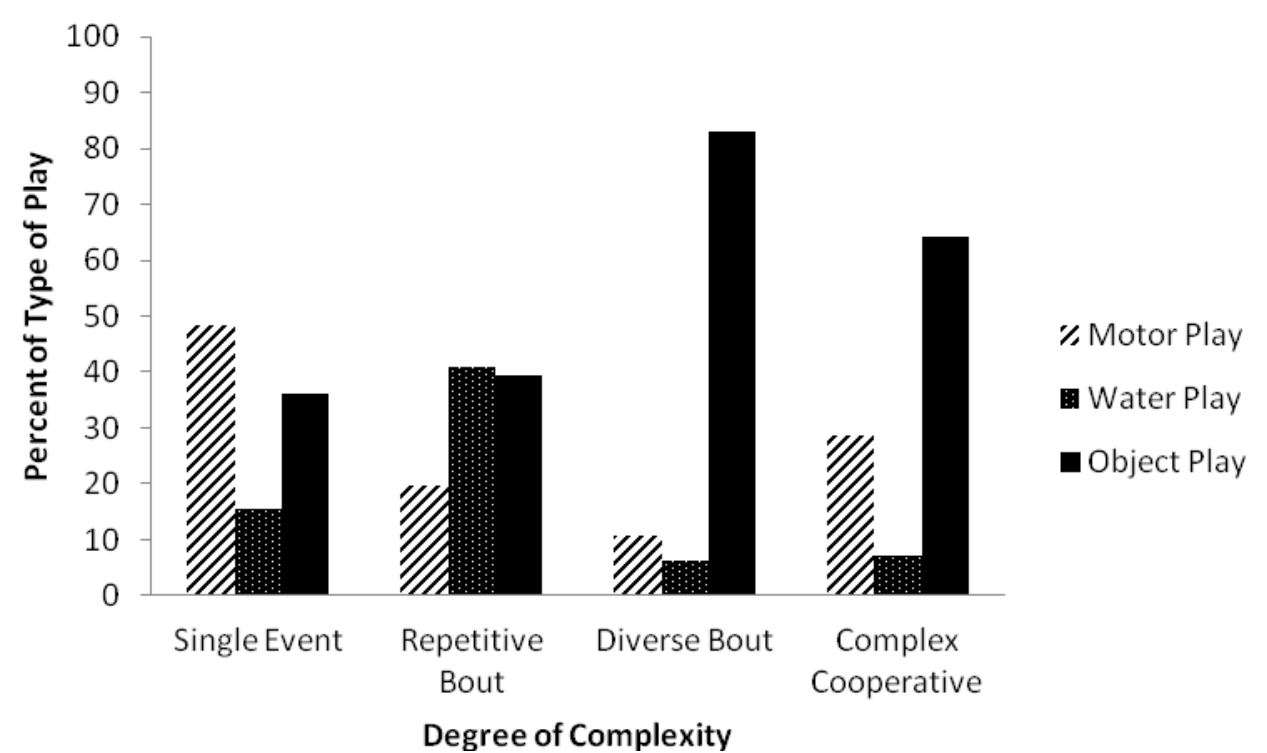

Figure 3. Percent of type of play per complexity of play category.

\section{Influence of age}

As expected, the results of a chi square goodness of fit test indicated that the immature belugas ( $n$ $=404,81 \%)$ exhibited significantly more play bouts than the adult belugas $(n=92,19 \%), \chi^{2}(1, N=496)$ $=213.66, p<0.001$. When the relationship between type of play and age were assessed for each degree of complexity of play significant associations from a series of chi square tests of independence were found for three of the four categories of complexity (Figure 4 A-D). For the least complex category of single event play bouts, the immature belugas preferred to engage in locomotor play $(n=95,56 \%)$ while the adult belugas preferred to engage in object play $(n=29,71 \%), \chi^{2}(2, N=211)=27.70, p<0.001, \mathrm{~V}=$ 0.36 . For the slightly more complex category of repetitive play bouts, the immature belugas preferred to engage in water play $(n=19,40 \%)$ while the adult belugas preferred to engage in object play $(n=9$, $75 \%), \chi^{2}(2, N=59)=6.37, p=0.04, \mathrm{~V}=0.33$. The most diverse solitary form of play, diverse play bouts produced results that approached significance, $\chi^{2}(2, N=171)=5.48, p=0.06, \mathrm{~V}=0.18$. The immature belugas displayed more diverse bouts involving locomotor play $(n=19,14 \%)$ whereas the adults generally displayed more diverse bouts involving object play $(n=31,91 \%)$. Finally, the most complex 
category of play, complex cooperative social play reversed the previous trends, indicating that immature belugas were more likely to engage in object play with others $(n=27,73 \%)$, while the adult belugas were more likely to engage in locomotor activities with others $(n=4,100 \%), \chi^{2}(2, N=41)=12.09, p=$ $0.002, \mathrm{~V}=0.54$.

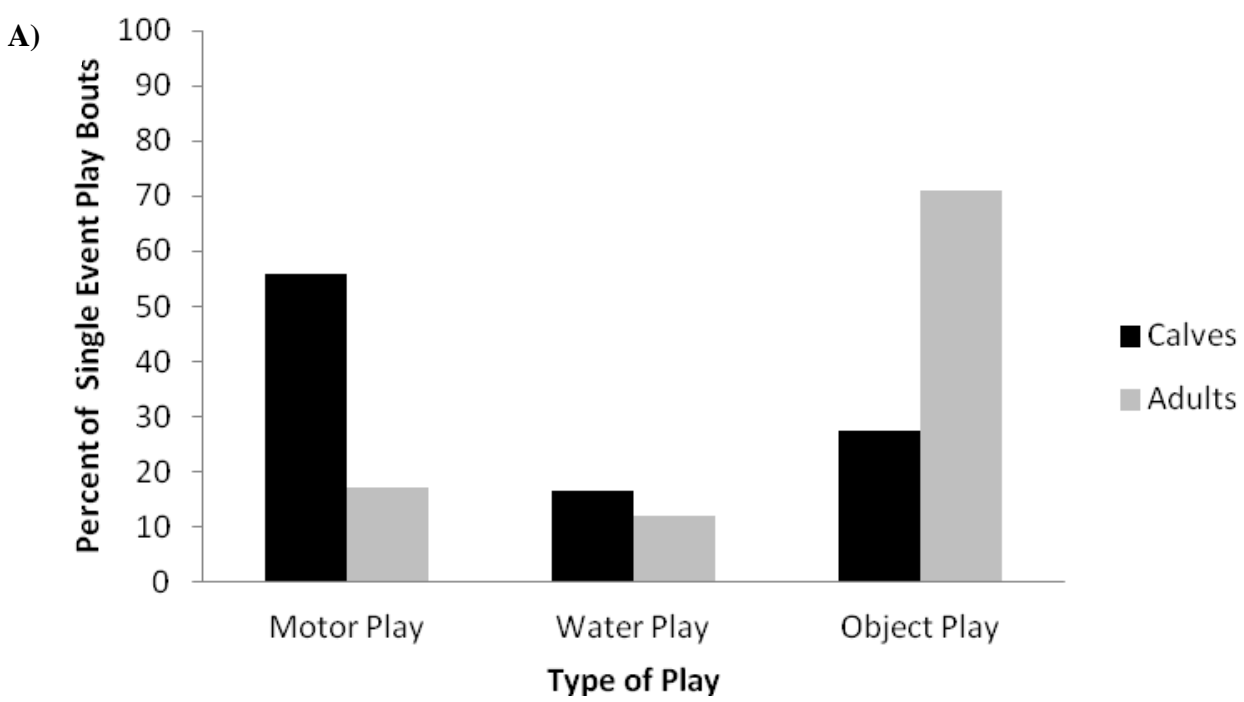

B)

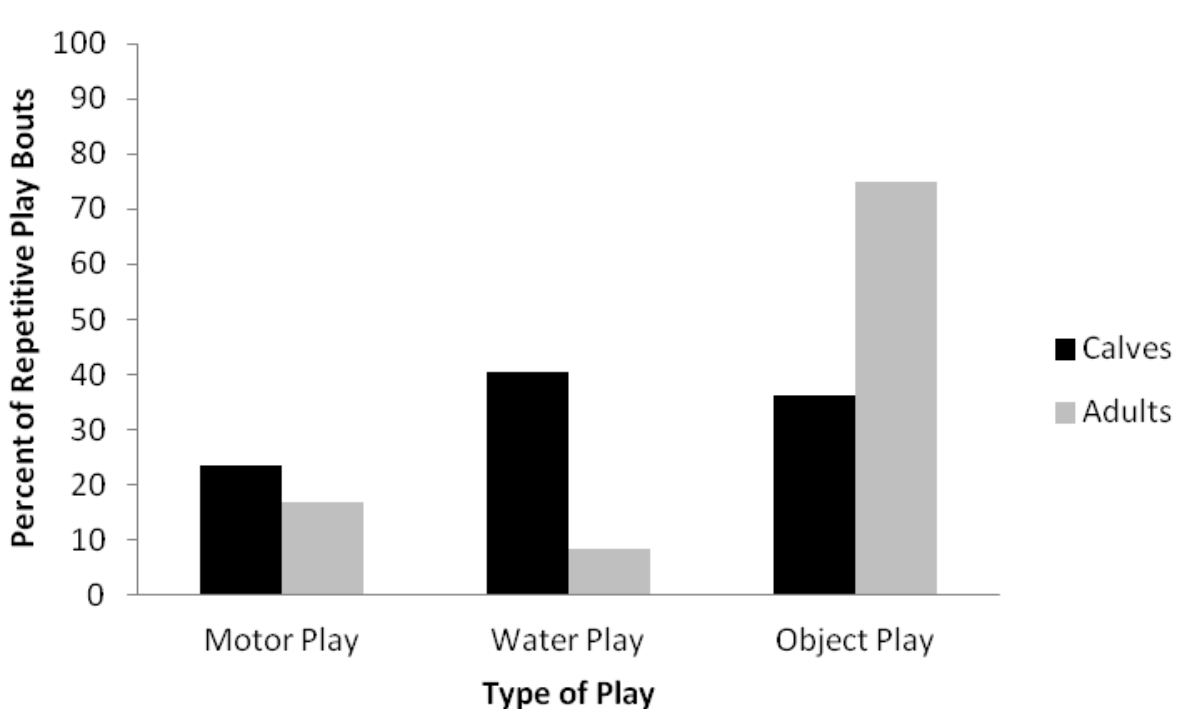




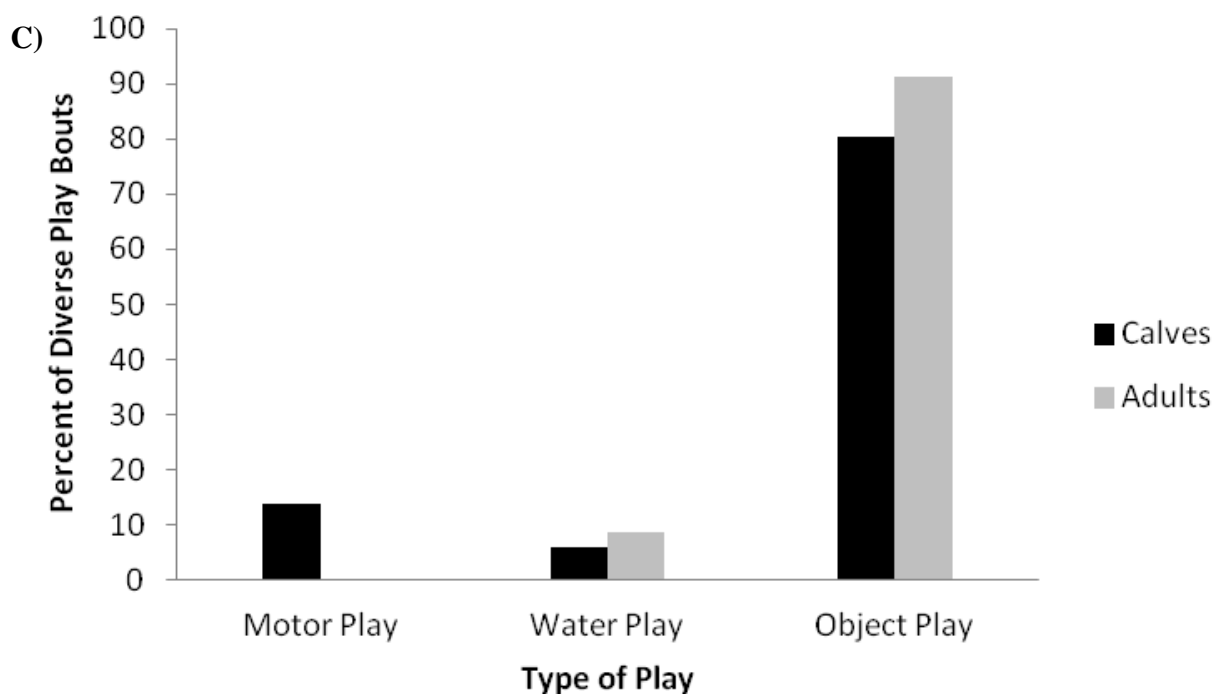

D)

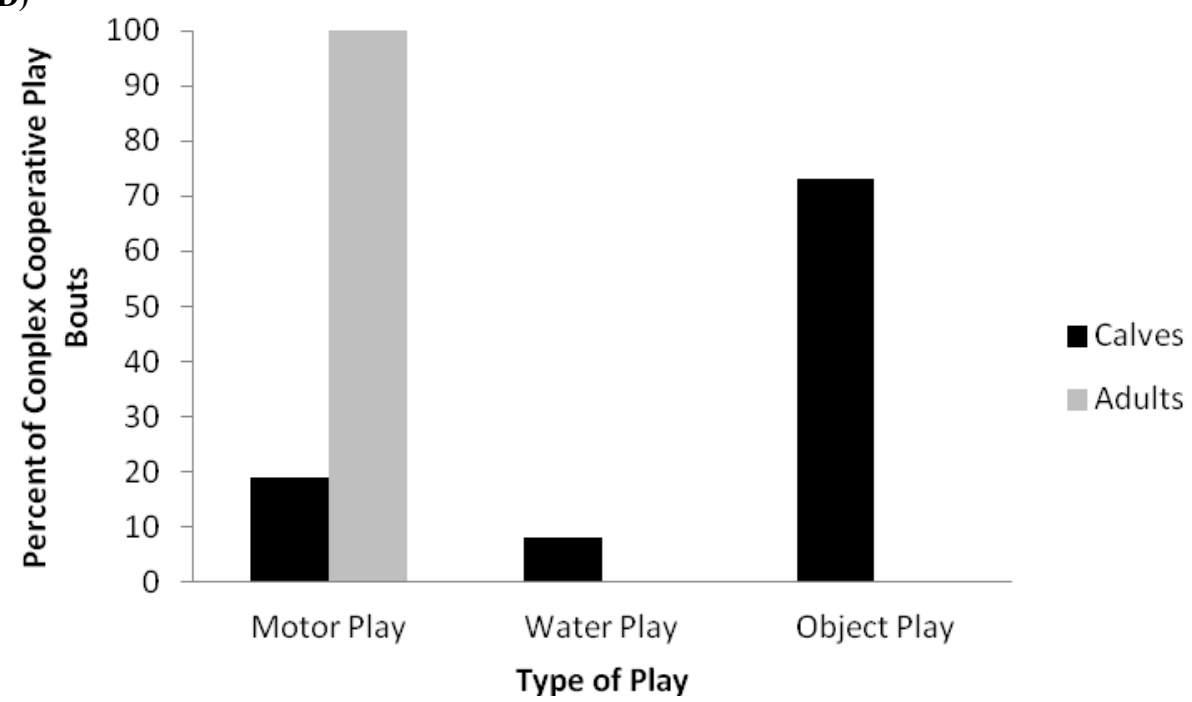

Figure 4. Percent of type of play per age for each complexity of play category. A) Breakdown of percent of type of play for mature and immature belugas displaying single event bouts. B) Breakdown of percent of type of play for mature and immature belugas displaying diverse play bouts. C) Breakdown of percent of type of play for mature and immature belugas displaying repetitive play bouts. D) Breakdown of percent of type of play for mature and immature belugas displaying complex cooperative/social play bouts.

\section{Influence of sex}

As expected, sex differences emerged in the type of play behaviors exhibited by the belugas for single event bouts and repetitive event bouts per the results of a series of chi square tests of independence (Figure 5 A-D). For the least complex category of single event play bouts, male belugas preferred to engage in locomotor play $(n=68,64 \%)$ while the female belugas preferred to engage in object play $(n=$ $55,52 \%), \chi^{2}(2, N=211)=26.57, p<0.001, \mathrm{~V}=0.36$. For the slightly more complex category of repetitive play bouts, the male belugas preferred to engage in water play $(n=18,62 \%)$ while the female belugas preferred to engage in object play $(n=20,54 \%), \chi^{2}(2, N=66)=10.41, p=0.005, \mathrm{~V}=0.40$. The 
most diverse solitary form of play, diverse play bouts produced results that approached significance, $\chi^{2}(2$, $N=176)=4.72, p=0.09$. The male belugas tended to display more motor play $(n=13,16 \%)$ whereas the females generally displayed more object play $(n=83,86.5 \%)$, although these results must be interpreted with caution. Finally, the most complex category of play, complex cooperative social play, did not produce any differences between male and female belugas.
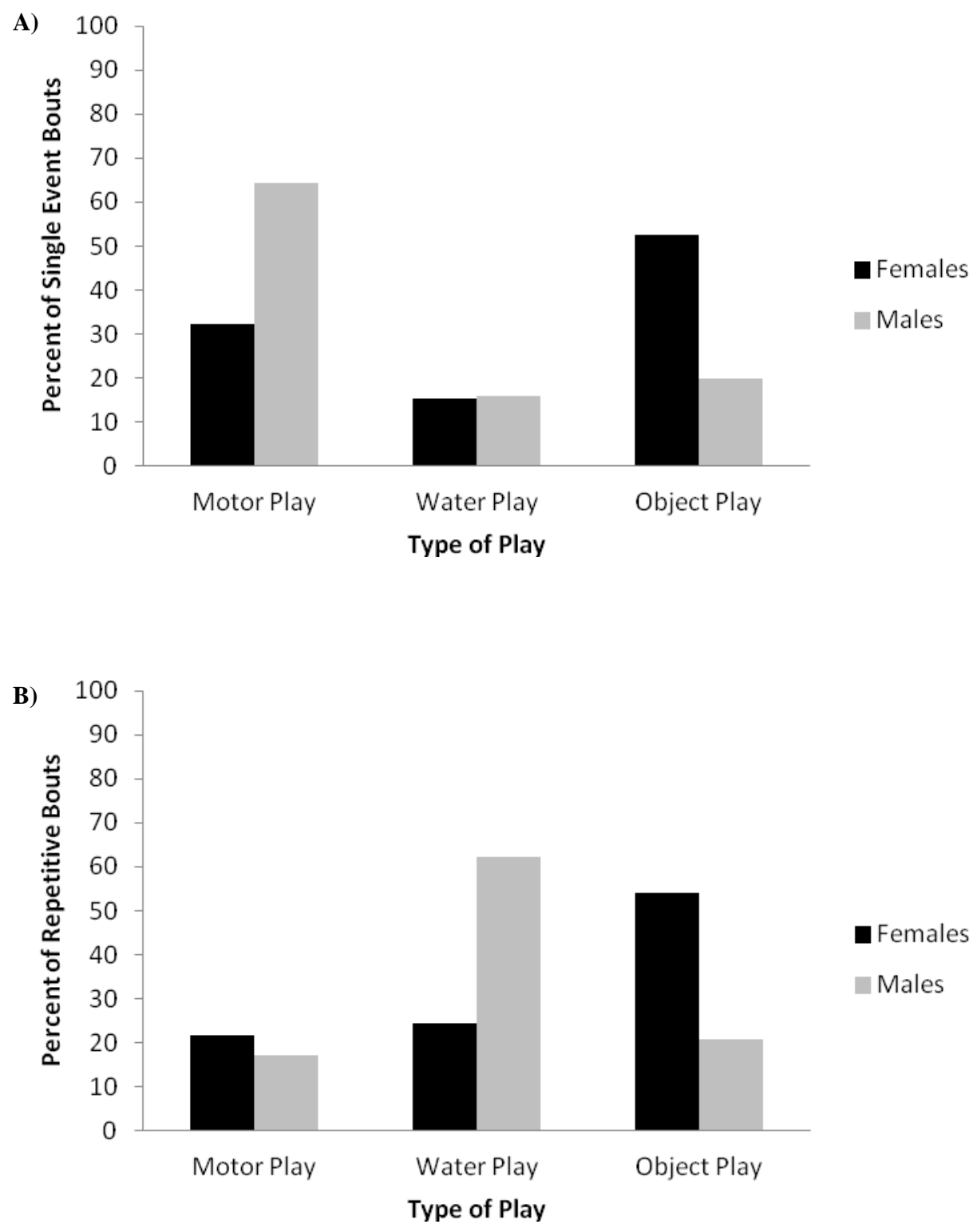

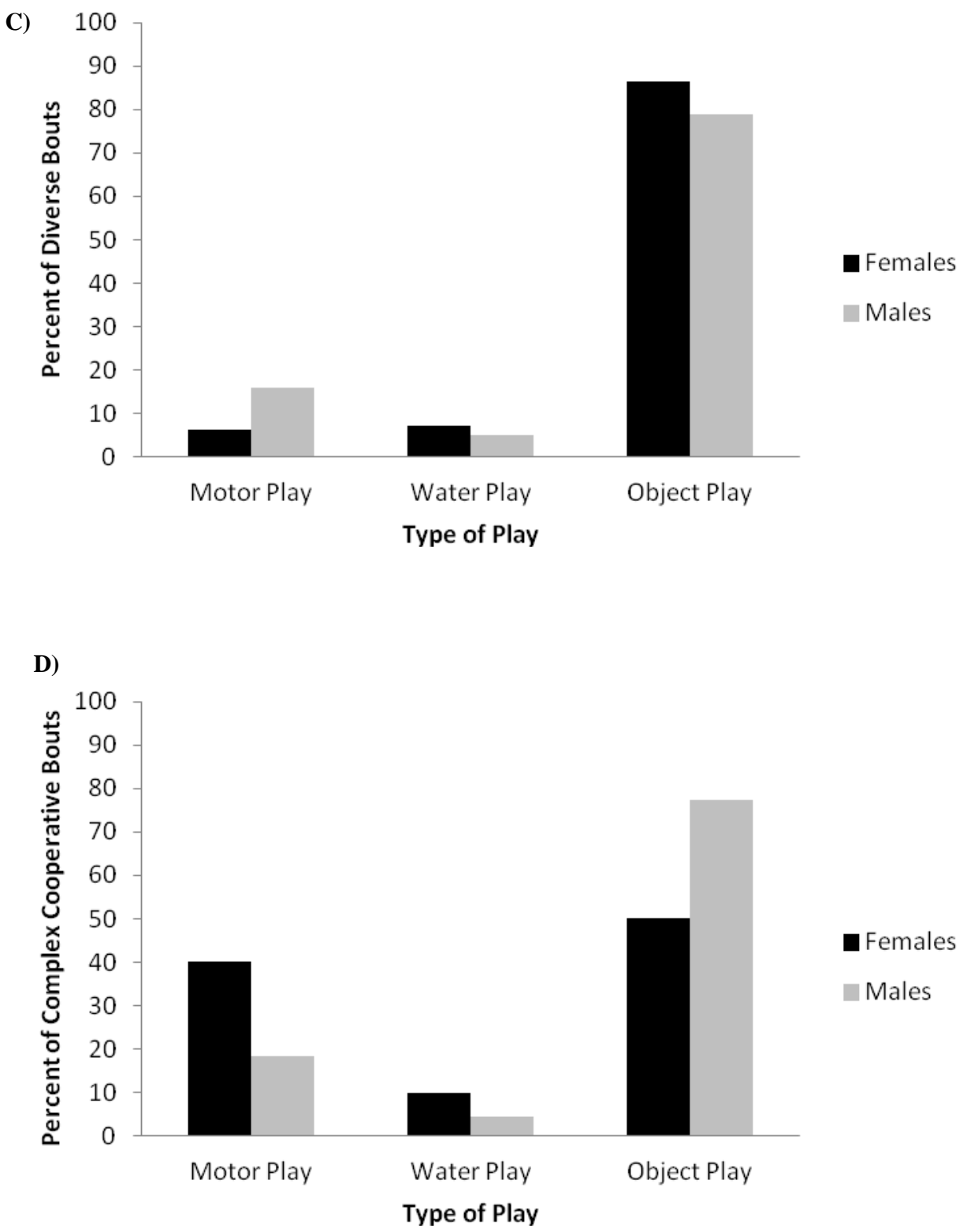

Figure 5. Percent of type of play per sex for each complexity of play category. A) Breakdown of percent of type of play for male and female belugas displaying single event bouts. B) Breakdown of percent of type of play for male and female belugas displaying diverse play bouts. C) Breakdown of percent of type of play for male and female belugas displaying repetitive play bouts. D) Breakdown of percent of type of play for male and female belugas displaying complex cooperative/social play bouts.

\section{Length of play bouts}

Although no hypothesis was formulated regarding the length of various play bouts, the influence of age, sex, type of play, and degree of complexity of play were assessed in an exploratory 4 (play bout) $\mathrm{x}$ 3 (type of play) x 2 (age) ANOVA. The results indicated that no significant main effect for age existed for duration. Immature belugas $(M=23.86 \mathrm{~s}, S E M=2.15)$ and adult belugas $(M=20.39 \mathrm{~s}, S E M=3.38)$ engaged in play bouts that were equal in duration. However, the results indicated a significant interaction for the type of play bout and level of complexity of play, $F(6,436)=2.35, p=0.031, \eta_{\mathrm{p}}=0.03$. A followup ANOVA with post hocs was performed to evaluate the relationship between these two variables and 
their effect on play bout duration. The Dunnet's T3 post hoc results indicated a very complex picture between the type of play and the degree of complexity (Figure $6 \&$ Table 3). Ultimately, the longest lasting and significantly different play activity occurred during diverse bouts involving object play $(M=$ $55.38, S E M=2.85$ ). The shortest lasting and significantly different play activity occurred during the single event bouts involving water play $(M=2.18, S E M=5.84)$. Also, as observed on the graph, a significant main effect for complexity of play emerged in the 3-way ANOVA, $F(3,436)=6.96, p<$ $0.001, \eta_{\mathrm{p}}=0.05$. A Bonferroni post hoc analysis indicated that single event bouts were significantly shorter in duration than diverse bouts (Table 3 ).

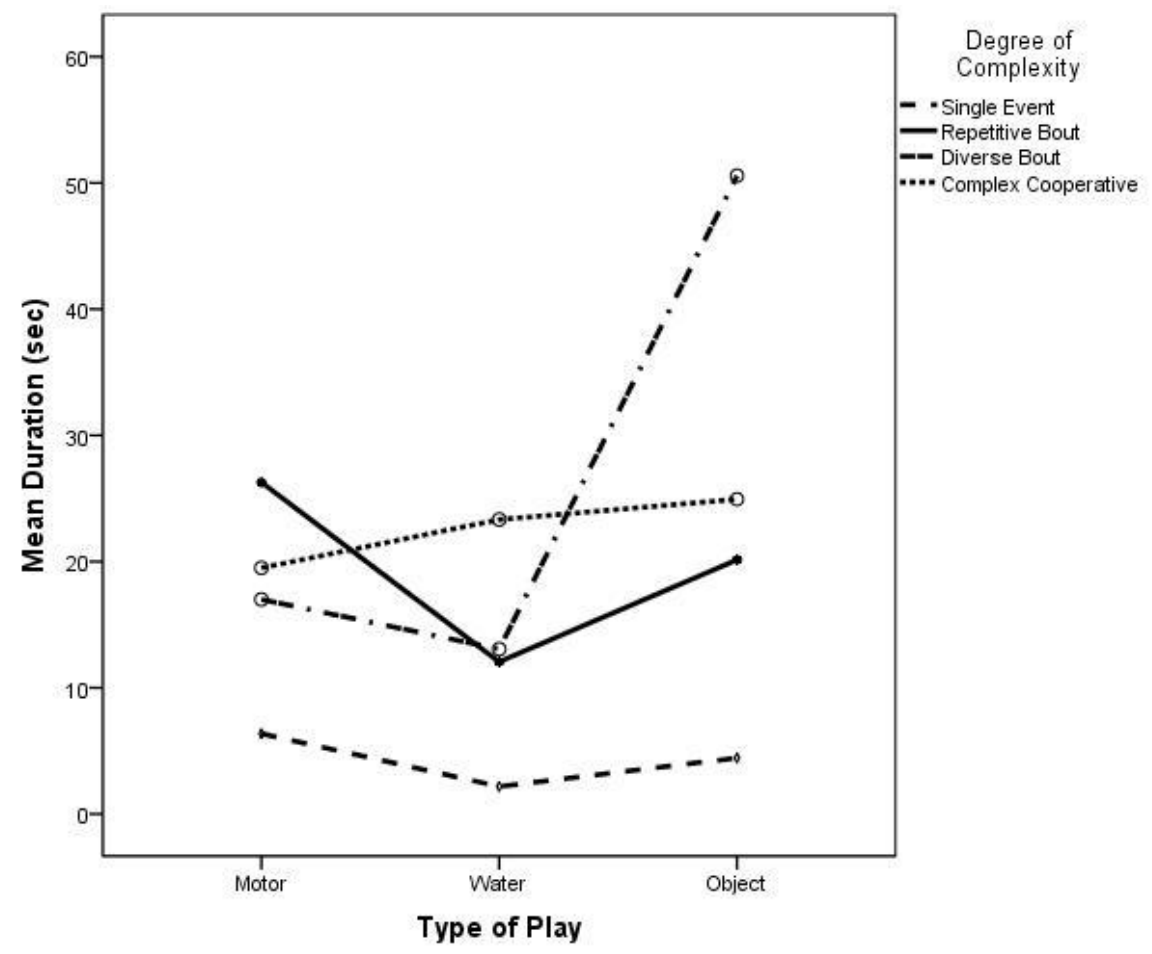

Figure 6. Mean durations (sec) of the interaction between type of play bout and complexity of play.

Table 3

Descriptive Statistics for Duration (sec) of Categories of Type of Play and Complexity of Play

\begin{tabular}{lcccc}
\hline & \multicolumn{1}{c}{ Motor } & Water & Object & Overall \\
\cline { 2 - 5 } Complexity of Play & M (SEM) & M (SEM) & M (SEM) & M (SEM) \\
\hline Single Event Bout & $6.37(3.34)$ & $2.18(5.84)$ & $4.45(3.89)$ & $4.36(2.57)$ \\
Repetitive Bout & $18.85(9.26)$ & $15.26(6.43)$ & $19.39(6.97)$ & $19.49(7.58)$ \\
Diverse Bout & $17.00(7.66)$ & $12.56(11.13)$ & $55.38(2.85)$ & $28.86(5.77)$ \\
Complex Cooperative Social Play & $10.50(10.56)$ & $23.33(19.28)$ & $24.94(8.10)$ & $21.82(8.54)$ \\
\hline
\end{tabular}

\section{Discussion}

Play activities in belugas have been addressed by a handful of studies investigating calf development and mother-calf interactions during the first year of life (Hill, 2009; Krasnova et al., 2009) and the frequency of a specific water play behavior called a bubbleblow (Delfour \& Aulagnier, 1997; but see Hill et al., 2011). Given the lack of research on beluga play, the purpose of the current study was to 
explore different facets of play behavior in a group of belugas in human care. Overall, the results from a group of 14 belugas consisting of immature and adult male and female belugas were similar to previous research on play by cetaceans and terrestrial mammals (Bel'kovich et al.,1991; Burghardt, 2005; Byers, 1984; Fagen, 1981; Greene et al., 2011; Hasset et. al., 2008; Herzing, 1997; Hill et al., 2011; Kuczaj \& Makecha, 2008; Kuczaj et al., 2006; Kuczaj \& Trone, 2001; Kuczaj \& Yeater, 2006; Mackey et al., 2014; Mancini \& Palagi, 2009; Rauw, 2013; Worch, 2012; Yeater \& Kuczaj, 2010).

Play behaviors accounted for $12 \%$ of the belugas' activity budget derived from the available minutes from all selected video footage. Thus, play occurred at a rate of 0.34 play bouts per minute across all belugas. When compared to the average amount of play for two beluga calves during their first year of life (Hill, 2009), the current older belugas produced play fairly consistently across observation periods. This trend corroborated the results of previous studies, which suggests that not only do captive animals have more opportunities to play they take advantage of this freedom by playing (Burghardt, 2005; Fagen, 1981; Greene et al., 2011; Hall, 1998; Himmler et al., 2013; Kuczaj et al., 2006; Mancini \& Palagi, 2009; Paulos et al., 2010). Also replicating previous findings, the belugas in the current study displayed significantly more spontaneous solitary activities than cooperative activities (Burghardt, 2005; Fagen, 1981). Cooperative complex social play activities occurred most often between mother-calf pairs and between immature belugas, but never between adult belugas.

\section{Types of play and degree of complexity}

Like many other animals, belugas displayed locomotor play, object play, and social play spontaneously. Overall, object play occurred at twice the frequency of the other types of play. Granted this type of play is often performed at the water surface and is therefore obvious, we do not believe it was over-represented. The belugas spontaneously manipulated other inanimate objects within their environment (e.g., fish, gates, leaves, feces, bugs) and would do so for extended periods, but they clearly preferred to interact with a variety of objects when the opportunity was presented. Similarly, while water play could be classified into object play, we examined it separately as water manipulation is a form of play special to cetaceans that provides opportunities to master a challenging behavior while also increasing the complexity of its actions (Kuczaj et al., 2006; Kuczaj \& Trone, 2010; Marten et al., 1996; McGowan et al., 2000). Beluga water play included producing different sized and number of bubbles and bubble rings as well as water tosses, water spits, water fountains occurred and did not occur as frequently (about 14\%) as object and locomotor play. It is likely that the frequency of water play was underestimated as most of the video footage was collected above the surface of the water and bubble play is difficult to observe from this vantage point. Another easily observable behavior, locomotor play constituted a quarter of the play activities observed and consisted of different types of fast-paced swims, vertical spins, slide outs, and some aerial behaviors. Finally, social play was observed but occurred the least often of all the play categories for belugas. Examples of social play in this sample of belugas included taking turns surfing on an underwater slideout, chasing one another across the pool, taking turns as chaser and the chased, interacting with an object together, such as tug-a-war with a gate or an EED. If an interaction appeared aggressive in nature, such that a receiving beluga fled away or removed itself to a "safe zone" or the receiving beluga responded with an equally aggressive response (e.g., an open mouth threat or head jerk), it was not included in the social play category.

The small number of social play interactions was somewhat surprising as belugas are reported to be highly gregarious animals (Krasnova et al., 2009; Norris, 1994) and many social mammals are reported to exhibit many types of social play, including play fighting, chasing, and socio-sexual activities (Burghardt, 2005; Fagen, 1981; Mancini \& Palagi, 2009; Pellis \& Pellis, 2013). The belugas in this study also engaged in play fighting, chasing, and socio-sexual activities. For example, the immature belugas exhibited a social play behavior in which two belugas of similar age class locked mouths while floating at the surface. The belugas then pulled back-and-forth as if playing tug-a-war. Interestingly, this behavior appeared during the first year of life and then re-appeared a couple of years later and has only been observed in young belugas (Dietrich, Garza, Hill, \& Aibel, 2013). Another example of social play 
involved a young adult female beluga and an immature male beluga exhibiting a "king of the hill" type of game in which the young adult female beluga floated on an underwater ledge while the immature male beluga swam rapidly to her creating a large pressure wave on which he surfed past her. The female beluga then chased him off of the ledge only to have the male promptly return to the ledge while she was away and surf on it until she returned. A final example of social play involves a combination of play fighting and chasing within a socio-sexual context between an adult male beluga and an immature male beluga. Belugas typically direct open mouth threats, bubble bursts, and vertical S-postures at animals they perceive as threats. However, they also produce similar but slightly varied behaviors during courtship activities (McKinnon, Dietrich, Hill, \& Aibel, 2013). During the social play bouts between the two male belugas, both males repeatedly exhibited a combination of courtship and aggressive behaviors including lateral swims in which they circled one another, fast charges at and by one another, open mouth displays, and attempted bites or rakes of each other's flukes. The two male belugas seemed to take turns as the initiator and when the interaction became more aggressive in nature, the immature beluga left the immediate proximity of the adult male for a period of time only to return shortly after to initiate a new social play bout. These examples support previous observations that social play often incorporates behaviors from other contexts into the play bout, such as locomotor behavior combined with socio-sexual behaviors or aggressive behaviors (Burghardt, 2005; Fagen, 1981; Pellis \& Pellis, 2013).

Complexity of play bouts was examined using four categories that increased in complexity of actions (Fagen, 1995; Mitchell, 1990): single event bouts, repetitive bouts, diverse bouts, and complex cooperative social play. The belugas displayed significantly more single event bouts than any other play bouts, expected by previous research (Burghardt, 2005; Fagen, 1981). These bouts were also significantly shorter in duration than any other complex form of play. As predicted by Fagen (1995) and Mitchell (1990), complexity of a bout depended on the type of play involved. For this group of belugas, objects provided by humans appeared to facilitate the amount of diverse play and complex cooperative social play exhibited. These types of play occurred more often and lasted longer when objects were present. Clearly the fact that the belugas will combine different types of play together (e.g., locomotor play with object play) or perform variations of the same type of play (e.g., a sequence of buoy ball play in which the beluga first holds the buoy in the mouth, then pushes it with the rostrum, then traps it with the body, to finally trapping it with the flukes) suggests that belugas can be flexible in their behavior much like bottlenose dolphins (Kuczaj et al., 2006; Kuczaj \& Trone, 2001). While much of this behavior may involve independent learning, it may also be influenced by observational learning (e.g., Kuczaj \& Yeater, 2006; Yeater \& Kuczaj, 2010). Future research should explore the mechanisms by which belugas develop these complex play behaviors.

\section{Influence of age and sex on play behavior}

As expected from previous studies investigating the role of age and sex on play behavior, play behavior was also affected by the age and sex of the beluga. Immature belugas exhibited play bouts four times as often as adult belugas, corroborating previous research with all animal taxa observed thus far (Burghardt, 2005; Fagen, 1981, Kuczaj et al., 2006; Kuczaj \& Trone, 2001). Differences also emerged when type of play was considered for each level of complex play category performed independently. Single event play bouts and repetitive play bouts produced results indicating that the adult belugas preferred to play with objects while the immature belugas preferred to engage in locomotor play and water play, respectively. The diverse bouts produced a similar age trend although the results were not significant. These results suggest that immature belugas may prefer to practice behaviors that will improve their physical strength and coordination before they focus their play on manipulating natural and foreign stimuli within their environments. In contrast, adult belugas already control their bodies efficiently and may prefer to enrich themselves using objects within their environment. When complex cooperative social play was considered, the trend was reversed between the two age classes. Thus, immature belugas preferred to engage in object play when interacting with a conspecific, often another beluga of similar age or his or her mother. Interestingly, adult and immature belugas engaged in play 
bouts that were equal in duration. Thus, when adult belugas play, they appear to play as long as immature belugas. Additional research on the emergence of these various types of play would be critical in determining the developmental sequence of the underlying behavioral systems in belugas and potentially other cetaceans (e.g., Burghardt, 2005).

Finally, sex differences in types of play also emerged for this group of belugas. Male belugas tended to display more locomotor play and water play than female belugas than expected by chance. In contrast, female belugas tended to display more object play than male belugas than expected by chance. These sex differences support previous findings in which males are more likely to engage in rough-andtumble play and play fighting than females (Burghardt, 2005; Fagen, 1981; Pellis \& Pellis, 2013). These results also duplicate the trend Greene and colleagues (2011) reported for their free-ranging population of spotted dolphins in which females were more likely to exhibit object play with naturally occurring in animate objects.

In summary, a group of beluga whales in human care displayed a variety of play behaviors about $12 \%$ of their observed time. Given the limited amount of data examined and the emphasis of the original video footage on mother-calf pairs, the results of this study should be interpreted with caution until validated with additional data and other belugas. However, it is certain that belugas in human care produce all major categories of play observed in most other animal taxa, including locomotor play, object play, and social play. Belugas in human care also vary the complexity of their play, preferring most often to produce independent play bouts and a limited number of cooperative bouts. Immature belugas also play more often than older belugas and likely experience periods of development in which certain forms of play are more likely than other forms, reflecting developmental changes in their physiology and neural growth (e.g., Burghardt, 2005; Pellis \& Pellis, 2011; Pellis, Pellis, \& Bell, 2010). A future study in which the emergence of play in belugas is evaluated would be useful. Finally, male and female belugas may show preferences in the forms of play they select to produce as different pressures may be guiding their interests. Thus, male belugas may practice locomotor and water actions that potentially aid in courtship and aggression (e.g., chases, fast swims, bubbles) while female belugas may prefer more object-oriented forms of play as they may facilitate cooperative interactions more easily.

\section{Acknowledgements}

We would like to thank SeaWorld San Antonio for their willingness to open their doors for us to observe their beluga population the last six years. We would also like to thank the St. Mary's University Undergraduate Research Office for their financial support of D. Ramirez to complete the coding and analyses of the data compiled for this project during a summer research fellowship. Finally, we would like to thanks Aby Arroyos and Kelsey Houtkooper for their assistance in coding the video footage. This research was supported by an internal grant from the St. Mary's University Summer Undergraduate Research Program awarded to D. Ramirez.

\section{References}

Altmann, J. (1974/1996). Observational study of behavior: Sampling methods. In L. D. Houck \& L. C. Drickamer (Eds.), Foundations of animal behavior: Classic papers with commentaries (pp. 177-217). Chicago, IL: University of Chicago.

Bateson, P. (1981). Discontinuities in development and changes in the organization of play in cats. In K. Immelmann, G. W. Barlow, L. Pertinovich, \& M. Main (Eds.), Behavioral development: The Bielefeld interdisciplinary project (pp. 281-295). Cambridge, UK: Cambridge University Press.

Bekoff, M. (1978). Social play, structure, function, and the evaluation of a cooperative social behavior. In G. Burghardt \& M. Bekoff (Eds.), The development of behavior: Comparative and evolutionary aspects (pp. 367-383). New York, NY: Garland.

Bekoff, M. (1995). Play signals as punctuation: The structure of social play in canids. Behaviour, 132, 419-429. 
Bekoff, M., \& C. Allen. (1998). Intentional communication and social play: How and why animals negotiate and agree to play. In M. Bekoff and J. A. Byers, (Eds.), Animal Play: Evolutionary, Comparative and Ecological Approaches. Cambridge, UK: Cambridge University Press.

Bekoff, M., \& Byers, J. A. (1998). Animal play: Evolutionary, comparative, and ecological perspectives. Cambridge, UK: Cambridge University Press.

Bel'kovich, V. M., Ivanova, E. E., Kozarovitsky, L. B., Novikova, E. V., \& Kharitonov, S. P. (1991). Dolphin play behavior in the open sea. In K. Pryor \& K. S. Norris (Eds.), Dolphin societies: Discoveries and puzzles (pp. 67-77). Los Angeles, CA: University of California Press.

Biben, M. (1998). Squirrel monkey playfighting: Making the case for a cognitive training function for play. In M. Bekoff \& J. A. Byers (Eds.), Animal play: Evolutionary, comparative, and ecological perspectives (pp. 161-182). Cambridge, UK: Cambridge University Press.

Biben, M., \& Champoux, M. (1999). Play and stress: Cortisol as a negative correlate of play in Saimiri. Play \& Culture Studies, 2, 191-208.

Burghardt, G. M. (1998). The evolutionary origins of play revisited: lesson from turtles. In M. Bekoff \& J. A. Byers (Eds.), Animal play: Evolutionary, comparative, and ecological perspectives (pp. 1-26). Cambridge, UK: Cambridge University Press.

Burghardt, G. M. (2005). The genesis of animal play: Testing the limits. Cambridge, MA: Bradford Books (MIT Press).

Byers, J. A. (1984). Play in ungulates. In P. K. Smith (Ed.), Play in animals and humans (pp. 43-65). Oxford, UK: Basil Blackwell.

Byers, J. A., \& Walker, C. (1995). Refining the motor training hypothesis for the evolution of play. American Naturalist, 146, 25-40.

Caro, T. M. (1980). Effects of the mother, object play and adult experience on predation in cats. Behvioral and Neural Biology, 29, 29-51.

Delfour, F., \& Aulagnier, S. (1997). Bubbleblow in beluga whales (Delphinapterus leucas): A play activity? Behavioural Processes, 40, 183-186.

Dietrich, S., Garza, S., Hill, H., \& Aibel, S. (July, 2013). Oral exploratory interaction: "The mouth game" - A developmental precursor to aggressive threats or courting behavior? Paper presented at the Animal Behavior Society Meeting (ABS), Boulder, Colorado.

Drea, C. M., Hawk, J. E., \& Glickman, S. E. (1996). Aggression decreases as play emerges in infant spotted hyaenas: Preparation for joining the clan. Animal Behaviour, 51, 1223-1236.

Fagen, R. (1981). Animal play behavior. New York, NY: Oxford University Press.

Fagen, R. (1995). Animal play, games of angels, biology, and Brian. In A. D. Pellegrini (Ed.), The future of play theory (pp. 23-44). Albany, NY: State University of New York Press.

Gamble, J. R., \& Cristol, D.A. (2002). Drop-catch behaviour is play in herring gulls, Larus argentatus. Animal Behaviour, 63, 339-345.

Gibson, Q. A., \& Mann, J. (2008). The size, composition and function of wild bottlenose dolphins (Tursiops sp.) mother-calf groups in Shark Bay, Australia. Animal Behaviour, 76, 389-405.

Greene, W. E., Mellilo-Sweeting, K., \& Dudzinski, K. M. (2011). Comparing object play in captive and wild dolphins. International Journal of Comparative Psychology, 24, 292-306.

Hall, S. L. (1998). Object play by adult animals. In M. Bekoff \& J. A. Byers (Eds.), Animal play: Evolutionary, comparative, and ecological perspectives (pp. 45-60). Cambridge, UK: Cambridge University Press.

Hasset, J. M., Siebert, E. R., \& Wallen, K. (2008). Sex differences in rhesus monkey toy preferences parallel those of children. Hormones and Behavior, 54, 359-364.

Heinrich, B., \& Smolker, R. (1998). Play in common ravens (Corvus corax). In M. Bekoff \& J. A. Byers (Eds.), Animal play: Evolutionary, comparative, and ecological perspectives (pp. 27-44). Cambridge, UK: Cambridge University Press.

Held, S.D.E., \& Spinka, M. (2011). Animal play and animal welfare. Animal Behaviour, 81, 891-899.

Herzing, D. L. (1997). Life history of free-ranging Atlantic spotted dolphin. Marine Mammal Science, 12, 576-595.

Hill, H. (2009). The behavioral development of two beluga calves during the first year of life. International Journal of Comparative Psychology, 22, 234-253.

Hill, H., Campbell, C., Dalton, L., \& Osborn, S. (2013). The first year of behavioral development and maternal care of beluga (Delphinapterus leucas) calves in human care. Zoo Biology, 32, 565-570.

Hill, H., Kahn, M., Brilliot, L., Roberts, B., Gutierrez, C., \& Artz, S. (2011). Beluga (Delphinapterus leucas) bubble bursts: Surprise, protection, or play? International Journal of Comparative Psychology, 24, 235-243. 
Himmler, B. T., Stryjek, R., Modlinska, K., Derksen, S. M., Pisula, W., \& Pellis, S. M. (2013). How domestication modulates play behavior: A comparative analysis between wild rats and a laboratory strain of Rattus norvegius. Journal of Comparative Psychology, 127, 453-464. doi: 10.1037/a0032187

Krasnova, V. V., Bel'kovich, V. M., Chernetsky, A. D. (2009). Formation of behavior in the White Sea beluga calf, Delphinapterus leucas, during early postnatal ontogenesis. Russian Journal of Marine Biology, 35, 53-59. doi: $10.1134 / \mathrm{S} 1063074009010088$

Kuczaj, S., \& Makecha, R. (2008). The role of play in the evolution and ontogeny of flexible communication. In D. K. Oller \& U. Griebel (Eds.), Evolution of communicative flexibility (pp. 253-277). Cambridge, MA: The MIT Press.

Kuczaj, S. A., Makecha, R., Trone, M., Paulos, R. D., \& Ramos, J. A. (2006). Role of peers in cultural innovation and cultural transmission: Evidence from the play of dolphin calves. International Journal of Comparative Psychology, 19, 253-277.

Kuczaj, S. A., II, \& Trone, M. (2001). Why do dolphins and whales make their play more difficult? Genetic Epistemologist, 29, 57.

Kuczaj, S.A., II, \& Walker, R. (2006). Problem solving in dolphins. In T. Zentall \& E. Wasserman (Eds.), Comparative cognition: Experimental exploration of animal intelligence (pp. 580-601). Cambridge, MA: MIT Press.

Kuczaj, S. A., II, \& Yeater, D. B. (2006). Dolphin imitation: Who, what, when, and why? Aquatic Mammals, 32, 413-422.

Loizos, C. (1967). Play behaviour in higher primates: A review. In D. Morris \& D. Bruce (Eds.), Primate ethology (pp. 176-218). London, UK : Weidenfeld \& Nicholson.

Mackey, A. D., Makecha, R. N., \& Kuczaj, S. A. (2014). The development of social play in bottlenose dolphins (Tursiops truncatus). Animal Behavior and Cognition, 1, 19-35. doi: 10.12966/abc.02.02.2014

Mancini, G., \& Palagi, E. (2009). Play and social dynamics in a captive herd of gelada baboons (Theropithecus gelada). Behavioural Processes, 82, 286-292. doi: 10.1016/j.beproc.2009.07.007

Mann, J., \& Smuts, B. (1999). Behavioral development in wild bottlenose dolphin newborns (Tursiops sp). Behavior, 136, 529-566.

Marten, K., Shariff, K., Psarakos, S., \& White, D. J. (1996). Ring bubbles of dolphins. Scientific American, Aug, 6569.

Martin, P., \& Caro, T. (1985). On the function of play and its role in behavioral development. Advances in the Study of Behavior, 15, 59-103.

McBride, A. F., \& Hebb, D. O. (1948). Behavior of the captive bottlenose dolphin, Tursiops truncatus. Journal of Comparative Physiology and Psychology, 41, 111-123.

McCowan, B., Marino, L., Vance, E., Walke, L., \& Reiss, D. (2000). Bubble ring play of bottlenose dolphins (Tursiops truncatus): Implications for cognition. Journal of Comparative Psychology, 114, 98-106.

McKinnon, M., Dietrich, S., Hill, H., \& Aibel, S. (July, 2013). Overlapping and contrasting topography of beluga sexual and agonistic interactions. Poster presented at the Animal Behavior Society Meeting (ABS), Boulder, Colorado.

Meaney, M. J., Stewart, J., \& Beatty, W. W. (1985). Sex differences in social play. Advances in the Study of Behavior, 15, 1-58.

Mitchell, R. W. (1990). A theory of play. In M. Bekoff \& D. Jamieson (Eds.), Interpretation and explanation in the study of animal behavior, Vol. 1: Interpretation, intentionality, and communication, (pp. 197-227). Boulder, CO: Westview Press.

Norris, K. S. (1994). Beluga: White whale of the north. National Geographic, 185, 2-31.

Pace, D. S. (2000). Fluke-made bubble rings as toys in bottlenose dolphin calves (Tursiops truncatus). Aquatic Mammals, 26, 57-64.

Palagi, E. (2009). Adult play fighting and potential role of tail signals in ringtailed lemurs (Lemur catta). Journal of Comparative Psychology, 123, 1-9. doi:10.1037/0735-7036.123.1.1

Parker, S. T., \& Gibson, K. R. (Eds.). (1990). "Language" and intelligence in monkeys and apes: Comparative developmental perspectives. Cambridge, UK: Cambridge University Press

Parker, S. T., \& McKinney, M. L. (1999). Origins of intelligence: The evolution of cognitive development in monkeys, apes, and humans. Baltimore, MD: Johns Hopkins University Press.

Parten, M. (1932). Social participation among preschool children. Journal of Abnormal and Social Psychology, 27, 243-269.

Patenaude, F. (1984). The ontogeny of behavior of free-living beavers (Castor canadensis). Zeitshrift fü̈r Tierpsychologie, 66, 33-44. 
Paulos, R. D., Trone, M., \& Kuczaj, S. A. (2010). Play in wild and captive cetaceans. International Journal of Comparative Psychology, 23, 701-722.

Pederson, J. M., Glickman, S. E., Frank, L. G., \& Beach, F. A. (1990). Sex differences in the play behavior of immature spotted hyenas, Crocuta crocuta. Hormones and Behavior, 24, 403-420.

Pellis, S. M., \& Pellis, V. C. (1987). Play-fighting differs from serious fighting in both target of attack and tactics of fighting in the laboratory rat Rattus norvegicus. Aggressive Behavior, 13, 227-242.

Pellis, S. M., \& Pellis, V. C. (1998). Structure-function interface in the analysis of play fighting. In M. Bekoff \& J. A. Byers (Eds.), Animal play: Evolutionary, comparative, and ecological perspectives (pp. 115-140). Cambridge, UK: Cambridge University Press.

Pellis, S. M., Pellis, V. C., \& Bell, H. C. (2010). The function of play in the development of the social brain. American Journal of Play, 2, 278-296.

Pellis, S. M., \& Pellis, V. C. (2011). Rough-and-tumble play - training and using the social brain. In A. D. Pellegrini (Ed.), Oxford handbook of the development of play (pp. 245-259). Oxford, UK: Oxford University.

Pellis, V. C., \& Pellis, S. (2013). Rough and tumble play. Scholarpedia, 8, 30363.

Piaget, J. (1951). Plays, dreams, and imitation in childhood. New York, NY: Norton.

Piaget, J. (1952). The origins of intelligence in children. New York, NY: Norton.

Power, T. G. (2000). Play and exploration in children and animals. New York, NY: L. Erlbaum.

Rauw, W. (2013). A note on the consistency of a behavioral play marker in piglets. Journal of Animal Science \& Biotechnology, 4, 1-6. doi: 10.1186/2049-1891-4-33

Siviy, S. M. (1998). Neurobiological substrates of play behavior: Glimpses into the structure and function of mammalian playfulness. In M. Bekoff \& J. A. Byers (Eds.), Animal play: Evolutionary, comparative, and ecological perspectives (pp. 221-242). Cambridge, UK: Cambridge University Press.

Sommer, V., \& Mendoza-Granados, D. (1995). Play as indicator of habitat quality: A field study of langur monkeys (Presbytis entellus). Ethology, 99, 177-192.

Spinka, M., Newberry, R. C., \& Bekoff, M. (2001). Mammalian play: Training for the unexpected. The Quarterly Review of Biology, 76, 141-168.

Tavolga, C. M. (1966). Behavior of the bottlenose dolphin (Tursiops truncatus): Social interactions in a captive colony. In K. S. Norris (Ed.), Whales, dolphins, and porpoises (pp. 718-730). Los Angeles, CA: University of California Press.

Walters, J. R. (1987). Transition to adulthood. In B. B. Smuts, D. L. Cheney, R. M. Seyfarth, R. W. Wrangham, \& T. T. Struhsaker (Eds.), Primate societies (pp. 358-369). Chicago, IL: University of Chicago Press.

Watson, D. M. (1998). Kangaroos at play: Play behavior in the Macropodoidea. In M. Bekoff \& J. A. Byers (Eds.), Animal play: Evolutionary, comparative, and ecological perspectives (pp. 61-95). Cambridge, UK: Cambridge University Press.

Worch, E. A. (2012). Play initiating behaviors and responses in red colobus monkeys. American Journal of Play, 5, 104-119.

Yeater, D., \& Kuczaj, S. (2010). Observational learning in wild and captive dolphins. International Journal of Comparative Psychology, 23, 379-385. 